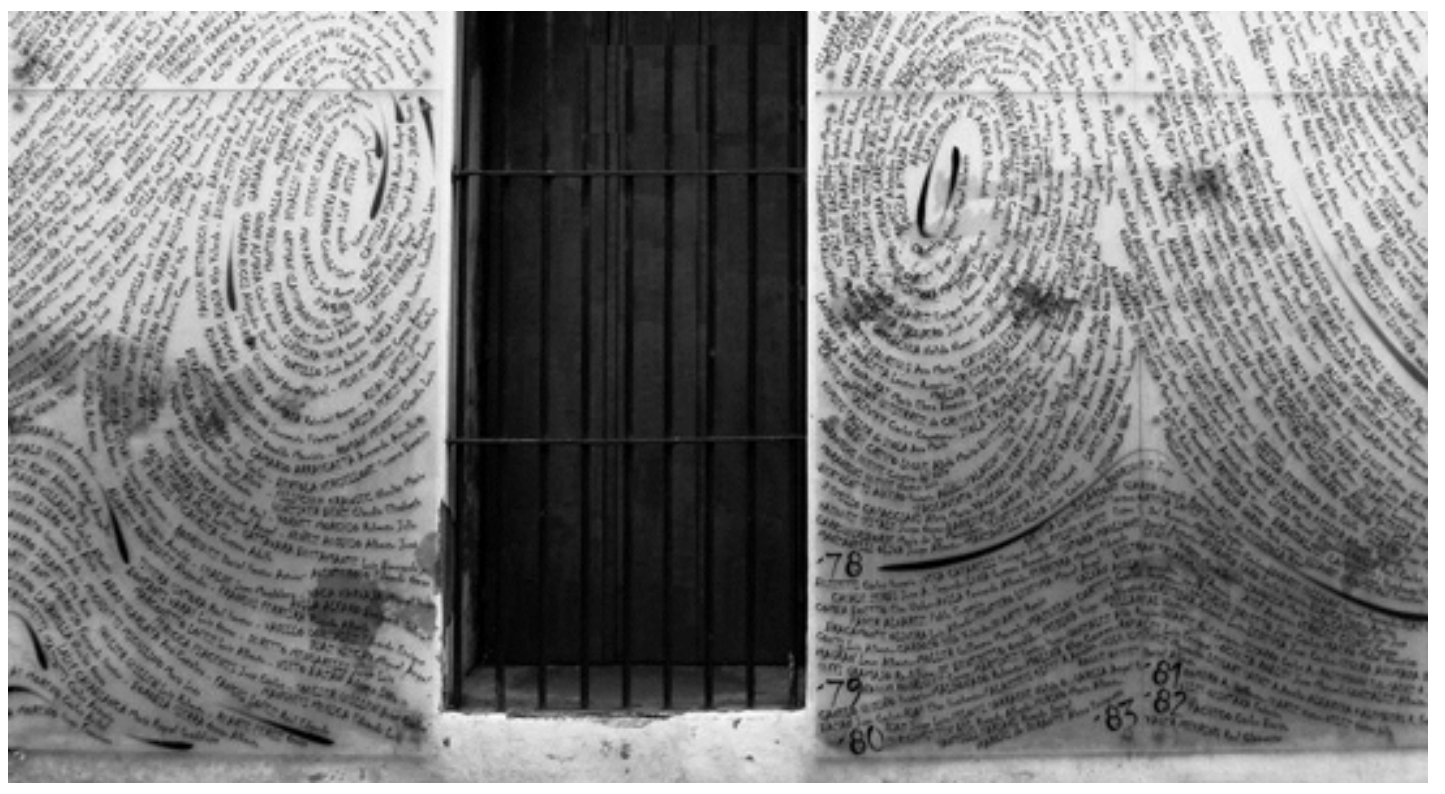

\title{
Do digital às digitais no Sitio de Memoria (Córdoba, Argentina): (re) interpretações da história política na cidade em movimento
}

From the digital to the fingerprints in the Sitio de Memoria (Córdoba, Argentina): the political History (re)interpretations in the city in movement

\section{Angela de Aguiar Araújo* Luciana Leão Brasil $^{* *}$}

\section{Resumo}

Para esta análise, são destacadas as "huellas" (representações gráficas de digitais presentes na fachada do museu Sitio de Memoria, em Córdoba, Argentina) que relembram pessoas desaparecidas durante os governos militares, no século XX. Mostrando para os pedestres fatos da história política da cidade, essas intervenções têm efeitos na narrativa urbana fazendo irromper o "corpo significante" da "cidade em movimento" em suas relações com os processos de identificação do sujeito urbano (ORLANDI, 2004).

Palavras-chave: Huellas; Narratividade Urbana; Efeitos de Sentido.

\begin{abstract}
For this analysis, it is detached the huellas (fingerprint graphic representations present on the façade of the Sitio de Memoria museum, in Córdoba, Argentina.) that recollect the missing people during the military governments, in the twentieth century. By showing for the pedestrians facts of the political history of the town, these interventions have effects on the urban narrative outbreaking the "significant body" of the "city in movement" in its relation with the processes of urban subject identification (ORLANDI, 2004).
\end{abstract}

Keywords: Huellas; Urban Narrative; Meanings Effects.

\footnotetext{
* Graduada em Comunicação Social / Jornalismo pela Universidade Federal de Minas Gerais - UFMG, mestre em Memória Social pela Universidade Federal do Estado do Rio de Janeiro - UNIRIO e doutoranda em Linguística pela Universidade Estadual de Campinas - UNICAMP. E-mail: angela.jornalista@gmail.com. Endereço postal: Rua Sérgio Buarque de Holanda, 571 - Campinas - São Paulo - Brasil.

** Mestre em Ciências da Linguagem pela Universidade do Vale do Sapucaí - UNIVÁS. Bolsista da Coordenação de Aperfeiçoamento de Pessoal de Nível Superior - CAPES. E-mail: leaobrasil@yahoo.com.br. Endereço postal: Rua Sérgio Buarque de Holanda, 571 - Campinas - São Paulo - Brasil.
} 


\section{Introdução}

Apresentar o objeto desta pesquisa e o recorte de análise proposto para este artigo implica no reconhecimento do momento em que nós, doutorandas em Estudos Linguísticos (cujo foco dos trabalhos se encontra na materialidade e nos processos discursivos) fomos instadas a questionar o modo de textualização de sentidos a constituir uma narratividade urbana (ORLANDI, 2004) no espaço da cidade ou, como aqui se pretende pensar, uma narratividade (histórica/da História/na história revisionista) urbana, bem como pontos de deslocamento / ruptura nessa narratividade discursividade.

O momento se deu no segundo semestre de 2011, quando, após dois dias de intensas reflexões teóricas sobre a memória, em evento científico realizado em Córdoba, Argentina, saímos caminhando pelo centro histórico-comercial da cidade. Estávamos muito afetadas/inquietas pelo forte apelo "revisionista" de uma história (considerada recente) e pelo predominante discurso da História, em um espaço - pretensamente multidisciplinar - de discussão, sobre a fecundidade da memória (esta vista como um objeto teórico para os campos que constituem as ciências humanas e sociais). Um apelo que por vezes parecia fazer sobrepor Verdade/História e Verdade/Memória. As inquietações resultavam da naturalização do sentido de verdade no discurso científico pelo qual também parecia ser efeito o sujeito histórico. Com a crença na possibilidade de uma história mais justa pelo ato consciente de (re)visão do passado (para impedir pela revisão de consciência a repetição dos erros do passado como uma "revisão de consciência", ou seja, um processo que seria desencadeador de "mais" consciência acerca da realidade), esse sujeito histórico parecia se constituir a partir de uma textualização marcada por inclinações morais e por julgamentos de valor - e com valor de "reconciliação"/de verdade. E, ainda, as provas ou as evidências que permitiriam falar de outra história (pelo ato de re-ver re-pensando o já pensado da história e na História) pareciam ser a garantia de uma realidade mais justa no presente e no futuro aproximando sentidos de História (com seus objetos de memória)/Justiça/verdade.

Estávamos no centro histórico e comercial da província de Córdoba. Em um zigue-zague sem roteiro pré-estabelecido, fomos aleatoriamente guiadas pelo encontro, aparentemente, espontâneo de placas explicativas dos marcos, históricos, pontos de 
ancoragem na indicação daquilo que, no espaço da cidade, é destacado como memorável (e, portanto, digno de um tratamento que permite sua preservação) pelo trabalho das ciências e/ou das políticas públicas dedicadas aos objetos da memória. Um relato que representa-apresenta-reapresenta, ao pedestre (habitante, turista, trabalhador, etc.), uma série de eventos - ainda que dispersos - permitindo assim interpretações que dariam contornos de significação para a história da cidade, tendo em vista o quadro crono-logicamente possível pelos elos passado - presente, antes - depois, causa consequência.

Em meio ao mosaico composto por imagens e por sons (placas, letreiros, publicidades, luzes, cores, carros, corpos, vozes, buzinas, músicas, plantas, edifícios, etc.), o histórico disputava sentidos para o urbano, num espaço onde o apelo comercial se impunha. Mas foi a partir do movimento de aproximação/distanciamento na tentativa de enquadramento (daquilo que nos parecia uma intervenção artística) para tomadas de fotos que algo se destacou: havíamos acabado de capturar algo na cena urbana a partir de "flagrantes de um olhar (um corpo) em movimento" (ORLANDI, 2004). Mas o que era esse algo? Estávamos diante das "huellas" (uma palavra, em espanhol, muitas vezes citada durante o evento em Córdoba, mas por nós desconhecida) ou, como um grito de um olhar sinalizou, "é uma digital".

A resposta daquela que, no quadro, se antepunha ao "visto" foi: “onde?" O questionamento foi seguido pelo apelo: "Veja atrás de você!" O gesto de enquadramento foi repetido algumas vezes por ambas até que percebemos uma placa que indicava ser aquele lugar um Sitio de Memoria, sítio este localizado na altura do número 64/66, no centro histórico, Pasage Santa Catalina: Museo de Sitio y El Archivo Provincial de la Memoria. Este lugar funcionou durante os anos 70 e início dos 80, como um Centro Clandestino de Detenção, tortura e extermínio. O espaço que hoje é ocupado pelo Sítio da Memória, foi conhecido como Departamento de Informações da Polícia de Córdoba (D2), segundo informações obtidas através do folder institucional distribuído no museu, organizado pela Comissão e Arquivo Provincial da Memória.

Durante o período acima mencionado, aproximadamente 20.000 pessoas teriam passado por ali, tendo sido detidas em razão da militância política. O Departamento de Informações da Polícia da Província de Córdoba (D2) foi criado para reprimir essa ação política considerada crime contra o regime político vigente à época, contra o governo e contra a província de Córdoba. 
O período de maior atividade repressiva ocorreu entre os anos 1974 e 1979, quando então o departamento esteve sob os cuidados do inspetor Ernesto Julio Ledesma (entre 1974 e 1975) e durante a derradeira ditadura militar (1976 - 1983), a cargo de Pedro Raul Telleldín (1975-1977), que ocupou a chefia do departamento também entre 1979 e 1980 e Juan Fernando Esteban (1977-1979).

A história argentina foi marcada pela perseguição política. A perseguição política já havia ocorrido em momentos anteriores, como em 1909, quando da Semana Roja, e em 1919, quando da Semana Trágica (1929-1921). No entanto, dos países do Cone Sul, é na Argentina que a atenção à violação dos direitos humanos e as tentativas de solução dos conflitos encontram-se mais avançadas.

O ano de 2006 foi conhecido pela aprovação, em 22 de março, da Lei 9.286, intitulada Lei da Memória (decreto regulamentado 873) quando então foram marcados os 30 anos da última ditadura militar argentina. Foi através dessa lei que o prédio, cujas instalações abrigaram o departamento de repressão política ao longo dos anos, cedeu lugar ao Museo de Sitio. Esse fato, conforme informações do folder institucional já citado, representou:

Un hecho histórico em el proceso de lucha de los organismos de Derechos Humanos. Lucha por la construcción de Memoria, Verdad Histórica, Justicia y Reparación Social ante las graves violaciones a los Derechos Humanos. (p. 4)

A lei 9.286 também instituiu uma Comissão Provincial da Memória. Essa comissão é formada por instituições e organizações, quais sejam: Abuelas de Plaza de Mayo; Familiares de Desaparecidos y Detenidos por Razones Políticas; Hijos e Hijas por La Identidad y La justicia contra El Olvido y El Silencio; Asociación de Ex Presos Políticos; Servicio de Paz y Justicia; Universidad Nacional de Córdoba; Poder Executivo; Poder Legislativo e Poder Judicial. Esses mecanismos são responsáveis pela organização de encontros mensais a fim de discutir os objetivos determinados pelas instituições.

Assim voltando ao fato de que o corpus em análise é fruto de algumas incursões na província de Córdoba, Argentina, inicia-se aí a nossa investigação, quando, a partir de um olhar estrangeiro, percebemos que na política (bem como no político que aí se configura pela divisão dos sentidos) do olhar, no deslizamento de algo que se dá ao/no sentido do digital à digital, o sentido "é também a janela de que se olha", deflagrando o "corpo significativo" da "cidade em movimento", ainda que a narrativa 
(histórica/da História/na história) tenha como efeito um "olhar organizado e organizador (do urbano) que é totalitário" (ORLANDI, 2004, p. 29-30). No próximo tópico, abordaremos alguns pressupostos teóricos da análise de discurso francesa, a fim de familiarizar o leitor frente a esse lugar teórico de estudo da linguagem, estudos dos sentidos, estudo da narratividade urbana, da memória (social e discursiva).

\section{Considerações sobre o método discursivo e a ideologia}

Este artigo traz como embasamento teórico os princípios e procedimentos da Análise de Discurso. Para essa teoria sujeito e sentidos se constituem simultaneamente como efeitos da interpelação ideológica na relação constitutiva língua e história. A Análise de Discurso surge como algo que propõe o deslocamento do foco de um fechado formalismo da linguagem, levando para o centro a relação com a exterioridade negada por esse. Com os estudos discursivos, a linguagem não é mais concebida como apenas um sistema de regras formais. A linguagem é pensada em sua prática, atribuindo valor ao trabalho simbólico e político, como sendo os sentidos algo movente e instável.

O que a Análise de Discurso procura pôr em observância é o caráter histórico da linguagem, visto que esse campo de estudo marca uma ruptura no campo da Linguística, implicando reconsiderações no objeto teórico língua na sua relação com o discurso. A Análise de Discurso de corrente francesa se constitui como uma disciplina de confluência em que se juntam três regiões de conhecimentos, quais sejam: o Materialismo Histórico, como teoria das formações sociais, inclui-se então a ideologia; a Linguística, como teoria dos mecanismos sintáticos e dos processos de enunciação; e por fim, a Teoria do Discurso, como determinação histórica dos processos semânticos. Não deixando de lado que todos esses elementos estão permeados por uma teoria não subjetiva do sujeito de ordem psicanalítica, pois o sujeito é afetado pelo inconsciente.

Ao serem abordados na teoria discursiva, tanto história, língua e ideologia quanto inconsciente deixam de ter o teor de sua origem ganhando novas dimensões e formulações para a compreensão do processo discursivo. Nesse ponto de vista, a Análise de Discurso jamais seria um instrumento para a mera explicação de textos. Nessa ótica de Pêcheux, o sentido não está claro, óbvio ou transparente, uma vez que é preciso considerar a opacidade (materialidade) aí presente e já que o sujeito não é nem intencional nem detentor do ilusório sentido literal. Diante desses pormenores da "instituição" da análise de discurso verifica-se o espaço do contraditório nessa 
disciplina de entremeio (ORLANDI, 2008, p. 68), pois a língua tem autonomia relativa e é a entrada para a materialidade do discurso. Para Pêcheux (1988), o sujeito do discurso não se pertence, ele se constitui pelo esquecimento daquilo que o determina, isso significando o fenômeno da interpelação do indivíduo em sujeito do seu próprio discurso.

\title{
3. História Recente e (Re) Significação
}

Segundo Vasconcelos (2009), em Memória Política, Democracia e Accountability: algumas reflexões teóricas, os anos 1980 deflagram um novo tempo para que se instalasse a democracia, tendo em vista o longo período de regime autoritário instaurado nos países do Cone Sul. Isso implica dizer que Brasil, Argentina, Chile e Uruguai, passaram por modificações em sua ordem política:

\begin{abstract}
Contudo, a perseguição e a repressão aos dissidentes políticos, em diferentes níveis de intensidade e alcance, estiveram presentes em todas as ditaduras da região. A "novidade" introduzida no aparato repressivo estatal, responsável por romper com a tradição autoritária precedente, foi o amplo uso do desaparecimento forçado de pessoas como estratégia de eliminação do "mal subversivo". Outras graves violações aos direitos humanos, como as prisões arbitrárias, as execuções sumárias, o uso da tortura e o sequestro de familiares fizeram parte do rol dos crimes operacionalizados pelos órgãos de repressão dos regimes autoritários (VASCONCELOS, 2009, p. 1).
\end{abstract}

A ditadura militar enquanto sistema político, no entanto, exibe seus rastros no processo de transição para um presente (regime político democrático) que procura construir um futuro esvanecendo as marcas de um passado de violência política. Violência que aponta questões não resolvidas na contemporaneidade expressas através de demandas históricas, da atualização dessas demandas por e para os sujeitos. Questões estas que são da ordem do discurso, que no presente caso, tornam-se objeto de análise ao ser pensado como as estratégias enunciativas para questionar essa história, através de uma narratividade, clamam por uma história verdadeira, mais verdadeira, justa que extrapola as esferas nacionais suscitando assim uma gama de discussões transnacionais apontando para a celebração/comemoração de valores universais com vistas à busca de um consenso nacional entre a ruptura com um passado de governos repressivos/violentos em prol de uma democracia comemorada através e com o auxílio dos movimentos sociais na aquisição de glórias futuras na pós-redemocratização. Segundo Vasconcelos (2008, p. 209), 
Os governos democráticos são pressionados por demandas por Verdade e Justiça por parte da sociedade civil organizada e os crimes cometidos pelas ditaduras militares estão longe de serem esquecidos especialmente na Argentina.

Assim a herança da violação de direitos humanos, acontecida ao longo dos regimes autoritários na década de 1970 na América do Sul, é uma demanda sempre em pauta em convenções nacionais e internacionais, não calando a voz de questões ainda a serem resolvidas. A democracia como um novo tempo político abre espaço para uma narratividade urbana revestida por um "dispositivo comemorativo (colóquios intelectuais, exposições artísticas, festas populares, etc.) implementado com o objetivo de celebrar o acontecimento na sua visão idealizada", segundo Silva (2002), em "Rememoração"/comemoração: as utilizações sociais da memória. Conforme Huntington (1994), tomado por Vasconcelos (2009, p. 210), "as novas democracias foram confrontadas com os crimes cometidos pelo regime anterior e se viram diante do dilema "processar e punir" versus "perdoar e esquecer."

Configura-se então uma narratividade atual(izada) daquilo que outrora foi um não acontecimento (o desejo da revolução, a não conquista da almejada revolução política) em virtude da violência produzida pelo aparelho repressor. Cobra-se da História (ou pelo viés da História) um dever de lealdade/fidelidade para com o sujeitotestemunho-testemunha dos fatos ocorridos que se materializam na democracia através dos lugares de memória.

A legitimação de uma verdade da história para o sujeito histórico (percebe-se que um legado anterior de desejo de revolução passa para a família enquanto herança agora de uma busca por justiça, não mais por revolução) que também é, por vezes, sobrevivente das grandes tragédias do século $\mathrm{XX}$ abre vistas para a narratividade também como dever, como inquietude, como vigilância. A narratividade urbana que se estabelece na delimitação do evento a ser revisado sobre a história recente, como poderemos observar nas fotografias abaixo relacionadas, tem a cidade enquanto espaço simbólico.

O espaço é aqui pensado não como pura geografia. O espaço este que vai além da sede, do âmbito do poder. Locus de população, onde há vínculos sociais, econômicos, culturais, políticos no qual sujeitos criam tradições. Mas espaço também como sítio de reflexão. O espaço aqui para nós é lugar (também) de confronto entre o simbólico e o político (Pêcheux, 1988), ou seja, o espaço como imaginário constitutivo 
dos processos de significação/identificação/individuação do sujeito (ORLANDI, 2004) na sociedade. Como acima referido o político nesta perspectiva de estudo é redimensionado significando a diferença que divide o social nas disputas de poder.

O espaço funciona como território para demarcar gestos de leitura, para constituição, para acolhimento dos sentidos e filiações nas práticas sociais. Desse ponto de vista é falta grave pensar que sujeito é uma coisa e espaço e cidade são outra. A linguagem, o sujeito e o espaço não desconversam ou apartam-se muito pelo contrário são conectados, constitutivos, ou seja, estão irmanados.

O espaço está num continuum. Deixa uma marca mesmo que solene, mesmo que permitida e até mesmo deixa o sinal do contraditório: o não delimitável, a possibilidade do acontecimento em vista de seu valor simbólico. Se o real da história, tal como formulado no campo da Análise de Discurso, é a contradição, uma proposta de estudo no campo desta teoria terá que se confrontar com o fato constitutivo da linguagem: a divisão dos sentidos e dos sujeitos. O funcionamento do discurso, em sua materialidade contraditória, se dá pela inscrição da língua na história.

Araújo (2011, p. 369), retomando Courtine (2006), descreve que a contradição "instaura a divisão ao mesmo tempo em que apaga o que divide os sentidos e os sujeitos tornando evidente a ilusão de unidade naquilo que imaginariamente se individualiza pela divisão. A contradição seria um funcionamento discursivo onde o lugar de produção de consenso corresponderia ao lugar de produção da diferença. Para o estudo da contradição, é preciso reconhecer que o outro atravessa qualquer tentativa de se formar, nomear, descrever, separar o um. Assim, o um não está só - por si mesmo ou em si mesmo - pelo fato de a heterogeneidade - contraditória - o constituir".

O espaço também aponta para fim de ciclos, círculos que deixaram palavras habituadas com um sentido já posto. Outrora, um centro de detenção, na atualidade, um Sitio de Memoria. Vasconcelos (2008, p. 236) aponta que

\begin{abstract}
Atualmente existe uma crescente mobilização social para que os locais usados pela repressão estatal se transformem em "lugares de memória" e permitam o conhecimento e a reflexão do passado recente da nação. Desta forma, está sendo construída em Buenos Aires uma espécie de "topografia da memória", de maneira a sinalizar, no espaço urbano, locais que simbolizem a luta pelos direitos humanos na Argentina.
\end{abstract}

Neste trabalho pensamos que não há somente uma sinalização, no espaço urbano, dos locais que simbolizam a luta pelos direitos humanos, mas há uma 
narratividade do urbano como marcas simbólicas que afetam a constituição do sujeito urbano a partir de um olhar organizador dos fatos históricos da cidade.

Entender a opacidade que perpassa uma instalação artística afixada sobre a fachada de um antigo Centro Clandestino de Detenção, que nos dias atuais funciona como um Sitio de Memoria, possibilita a "ressurreição" de efeitos de sentido adormecidos e de efeitos de sentido silenciados: um ex-centro de detenção que cede lugar a um Sitio de Memoria, um outro espaço enquanto natureza transformada.

O Sítio de Memória mostra a resistência no mesmo espaço (ex-centro de detenção), a resistência da cidade histórica de Córdoba (Sitio de Memoria) à organização urbana: a resistência do urbano, a resistência da narratividade urbana. Araújo e Ferreira (2012) ressaltam a importância daquilo que rompe com os discursos hegemônicos sobre a urbanização como possibilidade de irrupção de um novo dizer naquilo que se confira como a evidência do urban(izad)o. Assim a noção de espaço sítio não nos é validada simplesmente por aquilo se dá como evidência histórica de verdade, enquanto transparência dos sentidos na constituição do sujeito histórico e consciente, este resultante de mecanismos sustentados pelo trabalho político e científico em uma sociedade capitalista e democrática, onde se apregoa a garantia da igualdade de condições de enunciação e de participação para todos os cidadãos. Ao contrário, é enquanto espaço simbólico, marcado pelo político/pela contradição, que o sítio se mostra produtivo para esta análise.

Orlandi (2008) fala de uma ordem do discurso urbano. Essa ordem funciona no domínio do simbólico, pois se sujeita ao equívoco e, segundo a autora, há um real da cidade. Aí mora a questão da compreensão da narratividade urbana, seus gestos, enfim suas leituras. A autora menciona também uma organização urbana que se caracteriza por uma projeção do imaginário sobre a cidade que afeta os seres simbólicos em suas particularidades, quais sejam: urbanistas, administração pública, subjetivas.

Diante dessa organização urbana há toda uma construção empírica que não foge à regra: silencia as reais necessidades histórico-materiais do espaço enquanto ordem. Nós sujeitos, então, nos dispomos a ele. Desta forma, em razão da subjetividade do espaço, este se torna unidade e dispersão de sentidos, de sujeitos e de objetos. Como é o caso das "huellas".

Partindo da definição discursiva de espaço, assegurada por Orlandi (2004), enquanto espaço material, simbolizado em que sujeitos vivem, analisamos as fotografias e os enunciados que nelas constam. 


\section{As "Huellas"}

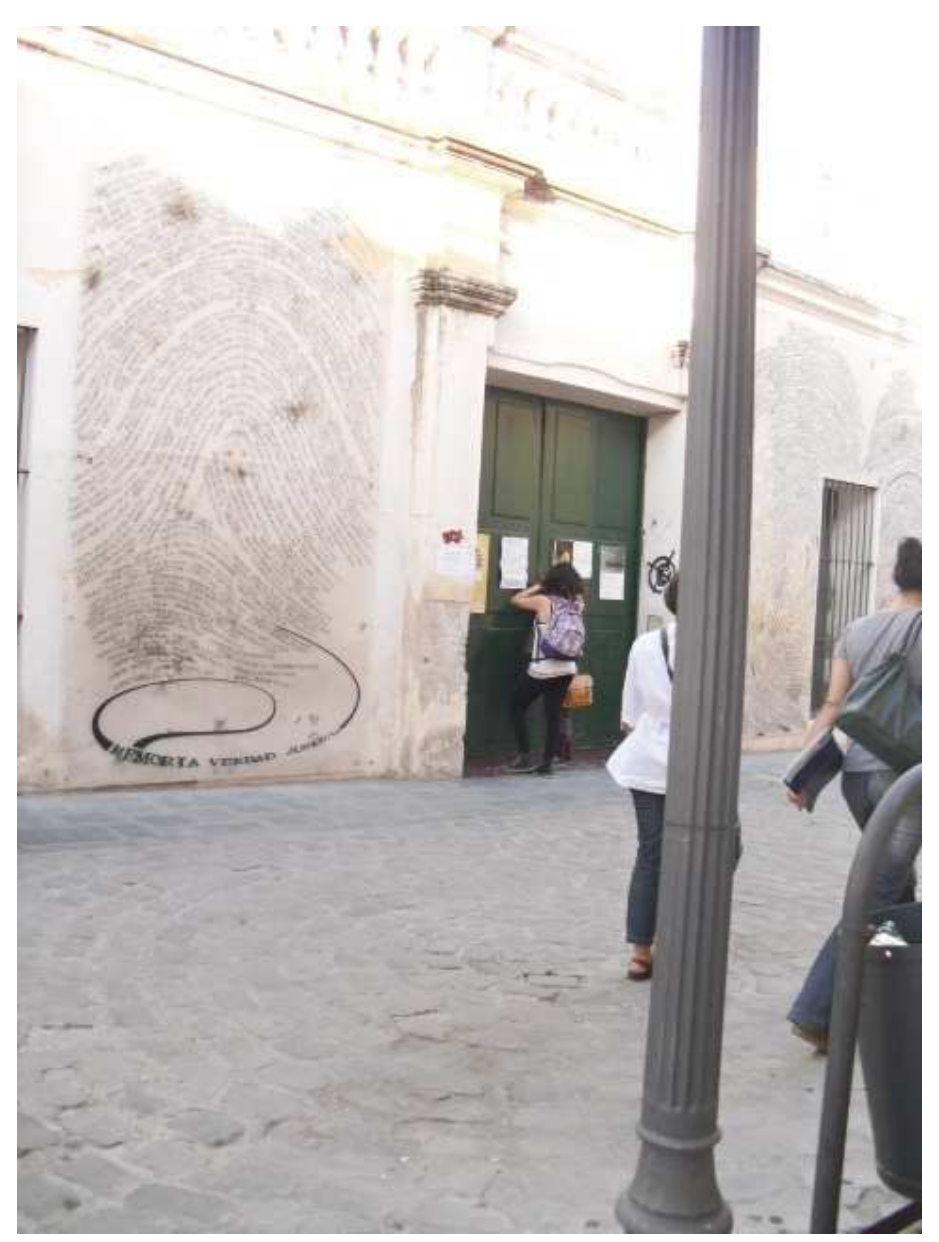

Fotografia 1 - A fachada do Sitio da Memoria

A fotografia ${ }^{1}$ de número 1 que vemos acima foi capturada diante do Sitio de Memoria. Em uma rua estreita, da histórica cidade argentina de Córdoba, somos convidados pela sinalização de um roteiro turístico (após nossa "familiarização" com a cidade de Córdoba) do histórico da história de Córdoba, uma normatização do espaço, apontados pelas placas que direcionam o nome de ruas, a trilhar o caminho não uniforme construído sobre blocos de paralelepípedos. Blocos organizados numa tentativa de diálogo com os movimentos circulares das "huellas". Esses blocos de pedras ora são arranjados por desenhos circulares, ora desarranjados entre os círculos que nos colocam diante do Sitio de Memoria de Córdoba, antigo Centro Clandestino de Detenção.

\footnotetext{
${ }^{1}$ As fotografias foram tiradas pelas autoras: Angela de Aguiar Araújo e Luciana Leão Brasil.
} 
O Sitio de Memoria de Córdoba nos permite pensar o quanto o espaço urbano se organiza de forma a fazer acontecer e comportar também um discurso mobilizado sobre a forma da arquitetura histórica que descreve uma periodização dos eventos do passado recente metaforizados em forma de instalações/intervenções artísticas. O Sítio de Memória acaba por propiciar ao transeunte não somente um contato com a história, mas um desdobramento da própria palavra sítio. Os efeitos do vocábulo sítio abrigam muitas significações:

1. Chão, lugar ocupado por qualquer corpo. 2. Chão descoberto; terreno próprio para quaisquer construções. 3. Qualquer lugar; localidade, povoação, aldeia, local. 4. Habitação rústica com uma pequena granja; morada rural; quinta. 5. Lugar assinalado por acontecimento notável. ${ }^{2}$

Podemos pensar a partir dos verbetes 1 e 5 um efeito de justaposição para abrigar discursos que estão em disputa pelo urbano. Se por um lado o sítio permite a visibilidade de um acontecimento histórico importante enquanto narrativa do urbano, ao mesmo tempo permite divisar a possibilidade da inserção de discursos derivados da forma como as estratégias sobre as quais se ancoram o que está sendo dito pelo sítio, como, por exemplo, a instalação dos painéis também artísticos, são abordados. Como por exemplo, também, o que a arte pode "dizer" sobre os painéis. Ao ser pensado o discurso da arte, não se pode afastar dessa compreensão o sítio enquanto visitação, enquanto lazer, enquanto uma forma de destacar o que acontece do lado de dentro e do lado de fora para quem caminha pela cidade.

Um conjunto aí se estabelece na dimensão cotidiana da cidade que circunscreve o que está sendo dito na narratividade funcionando como um percurso, tendo a cidade também como suporte do discurso. O centro da cidade, local em que o sítio está estabelecido, conjuga o lugar de comércio, de burocracia, de instituição, de turismo. O espaço aí funciona como mediador do que se narra para quem se narra os fatos da história. A narratividade aí se impõe como referência, pois diversas vezes em nossa estada em Córdoba, percebemos que as "huellas" são um modo de localizar lugares na cidade e formam uma identidade visual. É um modo também de dar visão às modificações do espaço e do movimento da cidade, da cultura da cidade.

Uma narratividade que alinhava o caminhar do cidadão ao caminhar da história numa estratificação socioespacial, numa estratificação entre o público e o privado. A rua

\footnotetext{
${ }^{2}$ Verbetes encontrados no dicionário on-line Michaelis
} 
onde se localiza o Sitio de Memoria por um momento perde o sentido de passagem ao interpelar, inicialmente, o sujeito pelo discurso da arte, para depois convocar o sujeito a embarcar na problemática discutida pelo sítio. O espaço então ganha sentido de reivindicação.

Segundo Tessler (2000, p. 33), em a Instalação Enquanto Lugar e o Lugar do Espectador, "o que é nebuloso na vida torna-se matéria-prima para a arte". O exercício do olhar em um princípio de leitura convoca o espectador num discurso das impressões sensoriais, da inquietação do olhar. Para Tessler uma instalação artística possibilita o encontro entre o verbo e o sujeito. O espaço urbano ordenado por nomes e ruas direciona sentidos, convidando para um percurso a ser traçado. O que o Sitio de Memoria faz é oportunizar flagrantes da vida e da história na criatividade da arte como potencializadora das impressões, das sensações, do que será visto dentro do Sitio de Memoria. A arte é uma mola propulsora, um dispositivo de interpelação ao conflito político tratado no sítio, um ponto de reflexão artístico-político.

Assim as digitais, enquanto instalações, permitem a obra de arte ir além do sentido de fruição, ampliando suas significações para a discussão de problemas sociais, modalizando assim o impacto a ser causado pelo que será visto dentro do museu: uma intervenção no espaço e na história. Tessler (2000, p. 34) então afirma que "estamos todos incluídos na obra, queiramos ou não, quando adentramos em seu espaço". O estímulo da arte funciona como um mediador de uma reação esperada por parte do público que visita o Sitio de Memoria. Tessler afirma que a instalação não toma o espaço, mas o reconstrói criticamente. Percebemos ao olharmos a fotografia 1 que somente a partir do afastamento corporal e do olhar para o Sitio de Memoria que conseguimos captar que os escritos formam digitais. É reconstruída então uma série de nomes que foram partícipes fundamentais dos acontecimentos narrados pelo museu. Abre-se espaço, via discurso da arte, para um memorável que caracteriza um lugar histórico. Ao longe parece uma digital, de perto convoca o sujeito para a leitura da escrita, como nota-se na fotografia de número 2. Desta forma, Tessler nos diz que a instalação provoca um cruzamento entre a arte enquanto objeto e a arte enquanto processo. O espectador, então, é quem vai dar sentido ao que se passa. Archer, tomado por Tessler (2000, p. 36), afirma que a significação: 
lugar no momento de encontro entre o espectador e um conjunto de estímulos. (idem)

A partir desses estímulos o olhar buscará os contornos de significação e isso é proporcionado pelo olhar de perto e de longe, entre o visível e o invisível dos painéis, aquilo que um pedido por Memória, Verdade e Justiça procura trazer para o exterior.

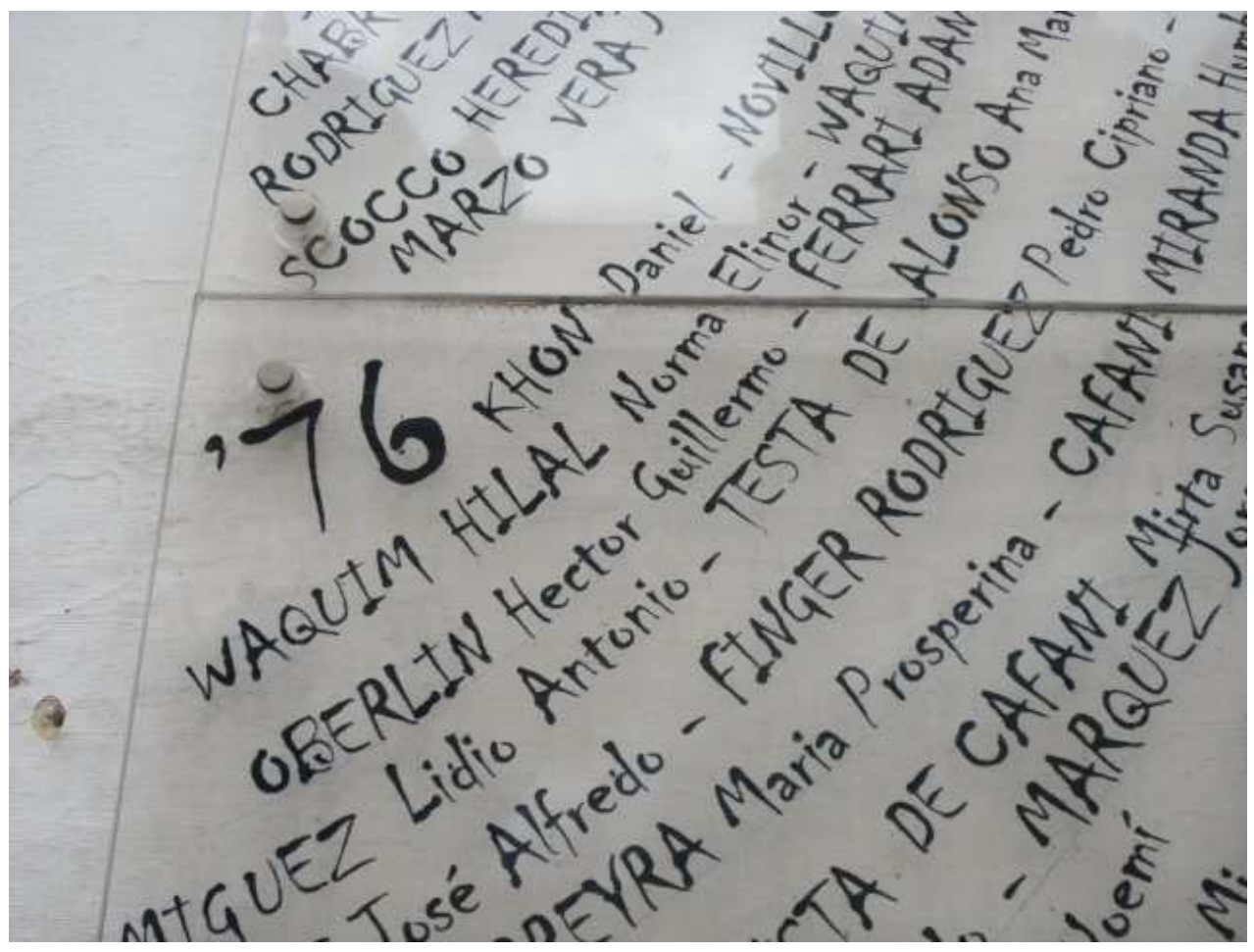

Fotografia 2 - Detalhe das Huellas

Notamos que de perto não nos confrontamos com digitais, mas sim com painéis transparentes que comportam nomes escritos em preto com uma fonte de escrita forte que descrevem nomes, sobrenomes e número (possibilitando vistas a um tempo histórico). O número imenso, numa posição primeira, vai chamando nome após nome como um sujeito, no início da frase, vai interligando os demais elementos da oração.

Nesta pequena rua, nas paredes do referido museu, os imensos painéis com a cravação de letras que simulam uma escrita à mão vão formando uma imensa lista de nomes individuais que formam um grupo de nomes de presos e desaparecidos políticos. O vocábulo 'desaparecido' traz para este contexto a menção a algo vago, impreciso, uma vez que o verbo encontra-se no particípio. O particípio de desaparecer anuncia um fato indeterminado não mostrando o causador, mas o resultado de um processo. É como efeito de resto daquilo que não existe mais, que as imensas digitais formam (se impõem como) um todo. Uma série de nomes dá forma/corporeidade, como vemos na fotografia de número 3, ao sujeito militante político preso - desaparecido - morto. Nesse jogo 
ausência - presença, se (re)configura o espaço de militância-reivindicação política: antes marcada pelos sentidos de clandestinidade/ilegalidade, agora uma espaço de exercício da cidadania; antes "ideia de revolução", agora a "garantia dos direitos humanos".

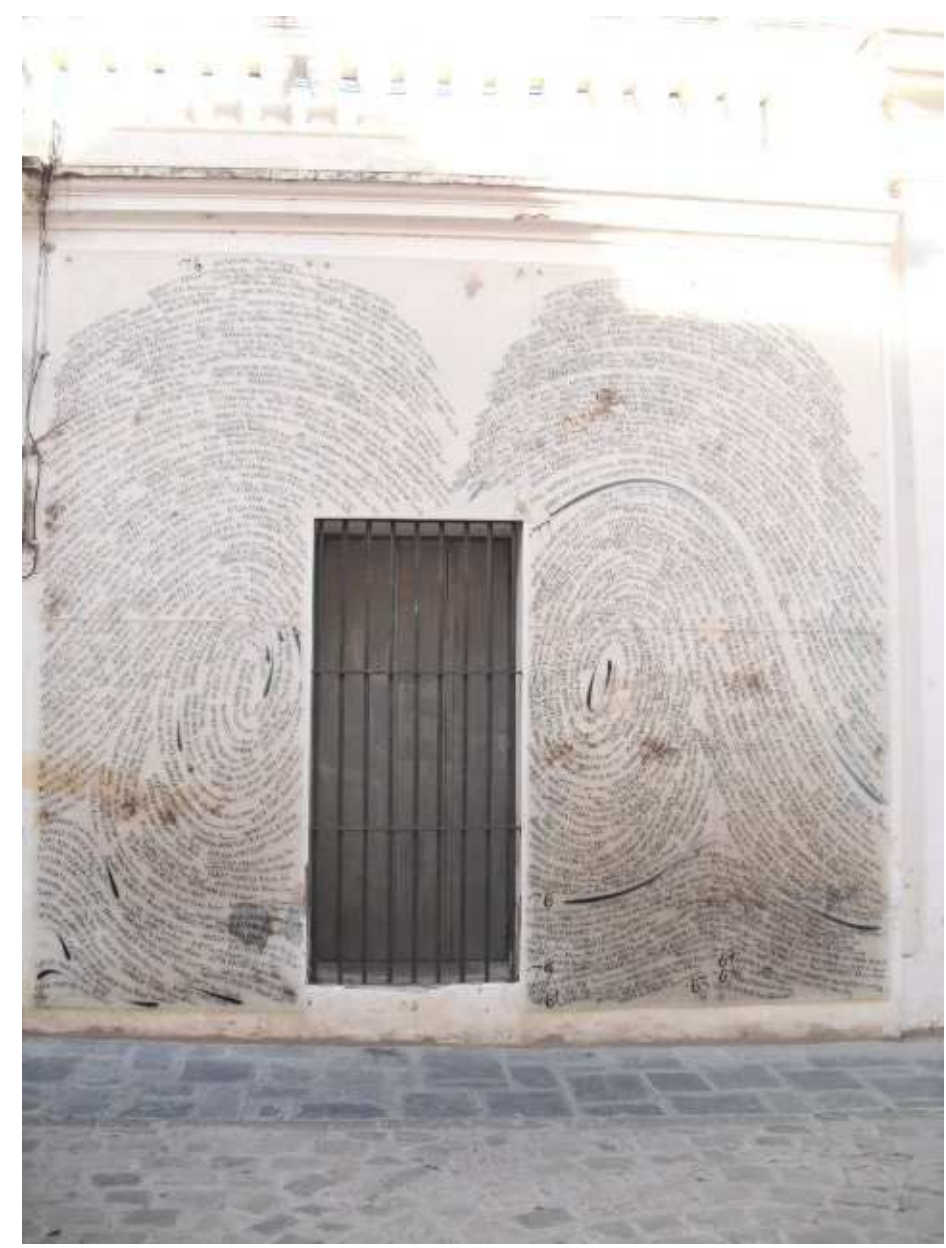

Fotografia 3 - "Las Huellas"

Segundo Sousa (2000, p. 22) em Caligrafias de uma Subtração, o que chamamos identidade "é a imagem por excelência da fragilidade, de algo que a todo momento ameaça se dissolver (...) a identidade é apresentada não como uma totalidade, mas como uma diferença”. Há algo que foi subtraído, portanto, há algo que falta. As formas das letras cravadas no suporte que comporta as digitais parecem vão desaparecer a qualquer momento escorrendo por entre a transparência, por entre as paredes. A tentativa então é a fixação à memória daqueles que por ali passam, num apelo à memória fotográfica. 
Segundo Peixoto (1999, p. 83) as intervenções urbanas vão possibilitar o surgimento, a seguir, de operações que redefinem a especificidade do sítio ao introduzirem um novo tipo de experiência espacial:

\begin{abstract}
A que leva em consideração as dimensões institucionais, econômicas e políticas do espaço, enfatizando suas contradições e conflitos. Ocorre uma extensão do conceito de sítio, para abarcar não só o contexto estético da obra, mas também os significados simbólico, social e político dos lugares, bem como as circunstâncias históricas nas quais obra de arte, observador e lugar estão inseridos. O sítio é toda a cidade vai além do prédio do museu.
\end{abstract}

Assim esses lugares não são lugares de neutralidade. O sítio indo além do caráter de lugar, mas como um espaço marcado pela linguagem, pela ideologia e pela política. Percebe-se que as intervenções artísticas funcionam como estratégia de chamamento do sujeito, da sociedade. A arte como um movimento de reconhecimento do itinerário da cidade. As digitais são um indício de realidade e de existência de um passado que não se quer esquecer apontando para uma futuridade: o desejo de justiça. A intervenção artística no urbano na tentativa de restituir a identidade. A digital com o nome dos indivíduos forma um todo na junção dos nomes; um mecanismo discursivo pelo qual "o um" projeta "o todos". As digitais são metáfora do silêncio dos desaparecidos: desaparecidos pelo regime e reaparecidos, com seus nomes, para o não esquecimento. As digitais produzem uma presença. Temos então um efeito metonímico: o todo pela parte/a parte pelo todo (as digitais pelo corpo); o efeito pela causa (o desaparecimento pelo desejo de revolução); as digitais pelo grupo; o nome próprio pelo familiar; o nome familiar/nome próprio pelo grupo de desaparecidos. Eduardo Guimarães (2002, p. 42) afirma que "quando um nome próprio funciona ele recorta um memorável que, enquanto passado próprio da temporalidade do acontecimento, relaciona um nome a uma pessoa". Nesse sentido, isso significa dizer que um nome evocado carrega a memória do acontecimento por ele evocado. Mais uma vez então o discurso dos desaparecidos se revitaliza e, neste momento, o tempo histórico já é outro, a redemocratização não é mais uma luta por mudança (a revolução), o que resta então é o desejo por uma justiça frente aos acontecimentos passados. Os sobrenomes familiares, em letras maiúsculas, anunciam uma heterogeneidade mostrada (a presença do outro, a família), somam-se a um concerto de vozes. A heterogeneidade aponta para a incompletude dos dizeres e dos sujeitos, aponta para a dispersão, mostrando uma maneira significante de corporificação do discurso outro. Assim a família é convocada para atualização das demandas do desaparecido. São os nomes que compõem uma 
sociedade. Segundo Authier-Revuz (1998), a heterogeneidade mostrada altera a unicidade aparente da cadeia discursiva, pois o outro é inscrito no discurso: a família é inscrita no discurso. As paredes já um pouco deterioradas da fachada do museu indicam o passar dos anos abrigando as digitais que formam um nós sem a respectiva filiação. $\mathrm{O}$ nós das digitais podem indicar: os mortos (impedimento de requerer justiça), os desaparecidos, a família; em contraposição com o eles (Estado, perpetradores, regime político).

No texto o Enlace entre o pictórico, o político e o textual, Indursky (2011, p. 2), tece uma explanação sobre a obra A Câmara Clara: nota sobre a fotografia, de Roland Barthes. Em seu texto, Indursky analisa os conceitos de Studium e Punctum, de Barthes:

O studium inscreve uma foto como testemunho histórico ou político. Já o punctum vem quebrar o studium. Ele faz parte da cena e de dentro dela atinge o espectador. "O punctum de uma foto, diz Barthes, é esse acaso que, nela, me punge, (mas também me modifica, me fere)" (BARTHES, 1980, 1984, p. 46).

Ao pensarmos sobre essas noções nos é possível propor que a fotografia das digitais apresenta características do que Barthes nomeia de studium a partir do momento que os painéis com as digitais são inscritos em um espaço e tempo precisos como um testemunho, através de uma representação, de um momento histórico-político. Assim o studium configura-se como um espaço para a reflexão, convocando ou não para o debate das questões não resolvidas historicamente aqueles que transitam pelo espaço urbano. Segundo a teoria proposta por Barthes, o punctum é da ordem da emoção. Esta é materializada através do contato com o que está escrito, a exemplo, nos painéis das digitais. O "leitor" então dessas digitais entrará em contato com as emoções que essas convocam em relação aos fatos do passado, no presente caso, um sistema político repressivo. É o punctum que rompe com a arte dos painéis apenas como fruição artística. É ele que desregulariza o que está sendo visto meramente como observação de um grafismo forjado por um artista, as digitais. O studium capta o histórico, o punctum apela para as discursividades que são produzidas a partir daí na incompletude do visual. As "huellas" produziram, então, um movimento de acionamento na memória discursiva.

A memória discursiva constitui-se de um conjunto de formulações feitas e já esquecidas que determinam o que dizemos (ORLANDI, 2007, p. 33). Isso implica dizer 
que para que o que falamos faça sentido é necessário que já faça sentido antes. A memória discursiva refere-se ao já-lá:

Existem sentidos já sedimentados que constituem o domínio da memória, do
já-dito, que por efeito ideológico, se apresentam como o conjunto de
evidências, de informações, de realidades reconhecidas e aceitas por todos, as
quais são codificadas pela língua de maneira mais clara e possível. É nesta
instância que os efeitos da objetividade e da literalidade são produzidos e que a
interpretação, ao mesmo tempo se dá, se apaga enquanto tal, criando a ilusão
de que esses sentidos são desde sempre assim e devem continuar assim para
sempre. Seria este o nível da interpretação constitutiva, do interdiscurso, da
ideologia, i. e., da História, nível inconsciente e ao qual não temos acesso
direto. História essa que não se situa, mas que consiste numa trama de sentidos.
(RODRÍGUEZ, 2003, p. 57)

Esse sentido já antes, os saberes anteriores, não nascem do sujeito. Segundo Payer (2003, p. 144), os saberes "nem habitam apenas o indivíduo isoladamente, mas remetem, também eles, à existência de um corpo histórico de traços discursivos que constituem o espaço memória". Segundo a autora as palavras modificam de sentido conforme o lugar de onde falamos (esse lugar faz parte tanto da memória, onde se encontram inscritos os sentidos, quanto de uma situação objetiva) e que "um sinal limite de distensão entre as memórias discursivas consiste justamente na atribuição de diferentes sentidos às palavras" (idem, p. 145). A memória discursiva é o lugar onde irrompem as transformações advindas do processo discursivo da interpretação. A memória discursiva faz parte de um processo histórico resultante de uma disputa de interpretações para os acontecimentos presentes ou passados. Para Courtine (1990), a linguagem é o tecido da memória. Há uma memória inerente à linguagem e os processos discursivos são responsáveis por fazer emergir o que, em uma memória coletiva, é característico de um determinado processo histórico. Assim o observador dos painéis produzirá associações a partir do que está vendo, recortando acontecimentos e relacionando sentidos da história política de Córdoba.

As digitais, forjadas por artimanha de um artista, eternizam algo que constitui uma discursividade ali presente (as "huellas") apontando para um lugar de exclusão, de (des) limite, de segregação (ORLANDI, 2009). Em A Casa e a Rua: uma relação política e social, Orlandi formula que a forma da cidade e a forma sujeito estão inseparáveis. Afirma que o modo como o espaço é disposto é uma maneira de configurar sujeitos em suas relações e de significá-los. Espaço em que os sujeitos e seus processos de identificação são interpretados pelo duo público/privado. Os painéis observam a cidade porque dela fazem parte. A escolha do par supracitado se deve ao 
fato de existir uma relação fortemente constitutiva entre a memória e o imaginário social do cidadão de Córdoba. Os sujeitos se filiam a discursividades em que há sempre uma urgência contraditória do olhar para a composição de sentidos. Não há "solução" para isso, pois estamos diante de reais - da língua (a incompletude) e da história (a contradição). O sujeito tem a sensação de que as coisas já fazem sentido, ou seja, o sentido dos efeitos ideológicos criados para os sujeitos e não pelos sujeitos:

A ideologia se movimenta justamente sob a paralisação do significado sob o significante (ou sobre, tudo é uma questão de ângulo), que produz o que Roland Barthes chamou de naturalização das significações, com perda de seu caráter histórico e contingente. (KEHL, 2004, p. 17)

Esta é a contribuição de um estudo ao nível discursivo, articular: sujeito, inconsciente, ideologia, simbólico, político. Enfim, uma constelação de conceitos que ora se fazem necessários para compreensão do estar social do indivíduo não só inserido, mas atuante e atravessado no espaço da cidade:

O corpo dos sujeitos está atado ao corpo da cidade e estes são significados por essa ligação. E de tal modo se articulam que o destino de um não se separa do destino do outro, em suas inúmeras e variadas dimensões: material, cultural, econômica, histórica etc. O corpo dos sujeitos e o corpo da cidade formam um só. Nosso corpo, urbano, que se textualiza como um corpo de cidade, ocupa um espaço e é ocupado por ele. (ORLANDI, 2004, p. 11)

O corpo do sujeito e o corpo da cidade estão intimamente unidos e essa relação é espacializada. Para Orlandi, o sujeito da cidade tem a forma sujeito histórica capitalista. Mas nem sempre foi dessa maneira a forma sujeito histórica ao longo da história em relação ao sujeito da contemporaneidade. Os indivíduos são afetados pela exterioridade, pelos movimentos dos sentidos do político, do Estado, das demandas sociais e tais processos estão presentes no modo como se constitui a subjetivação. Os estudos de Claudine Haroche (1992) elaboram um percurso histórico do modo como os indivíduos se tornam sujeitos. Durante o período que transcorreu entre a Idade Média e a Idade Moderna, em sua transitoriedade temporal, o Poder passou não mais a estar concentrado nas mãos da Religião. O Poder passou a estar nas mãos do Estado. Os ditames sociais vinham organizados conforme as leis divinas. Deus era a "voz de comando" à que o indivíduo se assujeitava. A organização social era construída segundo as leis dessa Voz. A obediência às leis divinas era o fundamento do estar no mundo do indivíduo. Em nome de Deus a sociedade era estamental. Em nome de Deus se escravizava. Em nome de Deus eram estabelecidas as diferenças de classe conforme a 
"benção" autorizada a cada indivíduo. A Revolução Francesa, divisor de águas, marco histórico da Idade Moderna, desorganiza a forma sujeito histórica: atribui ao Estado o arranjo social. A partir de então, as leis jurídicas ocupam o lugar das leis divinas:

Com o declínio da religião, da teologia, da ontologia, abandona-se o interesse dirigido a Deus, em proveito do homem, da natureza humana, mas, curiosamente, longe de se trabalhar diretamente na questão da subjetividade e de suas determinações, vai-se investir então em uma matematização desta. (HAROCHE, 1992, p.159)

O homem reificado se torna cidadão. Esse novo status quo, o sujeito propenso à sujeição da ordem jurídica, acarretou uma mudança no sentido do vocábulo Poder. Segundo Payer (2005, p. 08), o corpo também é visto sob um novo olhar, uma vez que este passa a ter importante papel como condição da livre circulação. A prerrogativa citada por Payer está vinculada a uma recompensa prometida para com a obediência civil: o tão almejado direito de ir e vir. Por outro lado há o reverso, a insubordinação, a punição ao corpo em desobediência à ordem jurídica: a prisão. Castigo irremediavelmente vinculado ao corpo, a sua interdição. O corpo é o cerne da possibilidade do ir e vir, do circular. O corpo que se movimenta com os seus efeitos de sentido, inscritos na história, é condicionado às explicações de sua pretensa liberdade, pautada pela responsabilidade de seus próprios atos. Livre sim, mas responsável.

Retomando Paul Henry, por Orlandi (2009, p. 03) o espaço é, de um lado, o enquadramento de todos os fenômenos e, de outro, ele não é um vazio, nem apenas uma função, ele é espaço de interpretação, tem sua materialidade na qual se confrontam o simbólico e o político. No espaço da cidade como se enquadram, não só os fenômenos, como falou Henry, mas acontecimentos onde o espaço faz parte das condições de produção. Orlandi (2009, p. 9), nos diz ainda que o espaço significa, tem materialidade e não está indiferente em seus distintos modos de significar, de enquadrar o acontecimento. As digitais funcionam como símbolo de iniciação, de novo começo, são um dos primeiros passos para existência em uma sociedade. Um símbolo de pertencimento a um outro espaço, a uma nova ordem. O espaço do existir, do ser, do estar assentado em uma sociedade civilizada, com reconhecimento das garantias próprias a todo cidadão. As digitais sinalizam condições para o pertencimento a essa nova situação: o ritual é o ganho da civilidade, marca da territorialidade e do reconhecimento de existência, a inscrição conforme as leis do Estado, uma personalidade jurídica. 


\section{Considerações Finais}

A impressão digital de cada indivíduo é única, mas isto fica em suspenso ao pensarmos as digitais dos painéis como símbolos da coletividade de sujeitos que formam um. A impressão das digitais é então um gesto de interpretação (im)posto na identidade/identificação de uma coletividade: cada nome sozinho pode nada significar, mas um conjunto de todos os nomes redobra a possibilidade de união de forças com um sentido de restituição (do "corpo", da dignidade, dos direitos, da possibilidade de dar forma, corpo e voz ao desaparecido, saindo do anonimato imposto pelo centro clandestino). Numa impressão digital, o sujeito se filia a redes de sentidos institucionais, a uma sociedade reconhecidamente de direitos e deveres. A digital enquanto marca do espaço urbano, na ambiência do urbano.

Jean Paul Thibaud (2008), em A Ambiência, trilhando caminho em direção a uma perspectiva internacional, elabora um novo olhar para o conceito de ambiência. A ambiência não pensada somente em suas particularidades (arquitetônica, puramente física, matematicalizada), mas em um alargamento de seu significado, propiciando a emergência do sensível e da experiência estética:

Ao proceder desse modo, ela tenta emancipar-se das perspectivas normativas demais em matéria de ambiente, fazer valer a atividade do sujeito da percepção e o papel das práticas sociais na concepção sensível do espaço construído, advoga em favor de abordagens plurissensoriais e torna possível uma atenção às situações ordinárias da vida urbana. (THIBAUD, 2008, p. 35)

Ambiência é fazer acontecer. Uma metáfora do olhar em que os fatos demandam sentidos: o olhar, o pensar, o refletir e o significar num trabalho intenso de interpretação. Assim as digitais podem permitir uma interlocução através da revelação de um espaço da cidade que aprofunda questionamentos: desenha um roteiro histórico, da história, na história ao dar a ver uma realidade desconhecida por muitos, mas ao mesmo tempo reconhecida por tantos outros. Uma narrativa histórica substitui um roteiro artístico e turístico desenhando um novo itinerário dos dizeres inscritos no urbano: nomes de presos, mortos e desaparecidos políticos que tomam forma de um. As digitais como um efeito de tecnologia que tenta restituir uma existência que estava na incógnita de um sistema político.

Gagnebin, em Lembrar Esquecer Escrever, a partir do estudo das obras de Paul Ricoeur, afirma que para o filósofo francês: 


\begin{abstract}
A história remodela a experiência do leitor por uma "reconstrução do passado baseada nos rastros por ele deixados", a partir de uma ausência, portanto enquanto a ficção transforma a experiência temporal a partir de sua preciosa irrealidade. Se ambas podem usar estratégias narrativas semelhantes, mecanismos de configuração parecidos ou mesmo idênticos, o momento de refiguração do mundo do leitor difere, sobretudo, no que toca à sua experiência temporal. (Gagnebin, 2006, p. 173)
\end{abstract}

Pensamos o leitor aqui enquanto o sujeito que se depara com as cenas da narrativa urbana da cidade de Córdoba, interpelado a partir do artístico na narrativa histórica não oficial. Paul Ricoeur, ao abordar essa tipologia (narrativa ficcional, narrativa histórica, configuração, refiguração) tendo como objeto e análise obras literárias. Para este trabalho a refiguração, que opera como uma modificação da experiência vivida através da narração, é cara ao pensar o confronto do sujeito com os dizeres postos em funcionamento em relação a um museu de memória que também outrora era um centro de detenção clandestino, uma vez que este interpelado pelo duo arte/política produz efeitos no que Ricoeur chamou de identidade narrativa, ao propor que esta não poderia portar-se como resultante do cruzamento entre história e ficção.

Percebemos, pelas análises que uma narrativa que se dá pelo urbano no espaço da cidade descreve a produção de uma identidade dos pertencentes à Província de Córdoba e um movimento na identidade dos que por ali passam, remontando a história política do seu local de origem: uma outra narrativa se inscreve em um tempo e na ação, como um efeito de universalismo de valores e problemas sociais, como um movimento ao centro a partir do periférico.

\title{
Referências Bibliográficas
}

ARAUJO, A. 2011. CPLP e o acordo ortográfico: o político no lingu[ü]ístico. Ado[p]tando uma unidade pacífica da língua portuguesa para além da fronteira do nacional. In: Língua Portuguesa, descrição e ensino: diálogos - Anais do X Fórum de Estudos Linguísticos da UERJ (2009). Rio de Janeiro: Dialogarts, pp. 367-376.

ARAÚJO, A.; FERREIRA, C. 2012. Entre sem bater: onde mora a beleza? In: Anais do III Seminário Nacional Literatura e Cinema de Resistência e III Mostra LatinoAmericana de Cinema de Resistência. Rio de Janeiro: Oficina Raquel, pp. 70-83.

AUTHIER-REVUZ, J. 1998. Entre a transparência e a opacidade. Um estudo enunciativo do sentido: Palavras incertas. As não coincidências do dizer. Campinas: Unicamp.

Comisión y Archivo Provincial de la Memoria. (2011, Novembro). http://www.apm.gov.ar 
GAGNEBIN, J. M. 2006. Lembrar escrever esquecer. Rio de Janeiro: Editora 34.

GUIMARÃES, E. 2002. Semântica do Acontecimento: Um Estudo Enunciativo da Designação. Campinas: Pontes.

HENRY, P. A. 1994. Ferramenta Imperfeita. Campinas: Pontes.

INDURSKY, F. 2011. O enlace entre o pictórico, o político e o textual. Enelin 2011 (pp. 1-10). Porto Alegre: Universidade Federal do Rio Grande do Sul.

KEHL, M. BUCCI, E. 2004. Videologias. São Paulo: Boitempo.

MARIANI, B. 1996. O PCB e a imprensa: os comunistas no imaginário dos jornais. Rio de Janeiro: Tempo Brasileiro.

NORA, P. 1993, Dezembro. Entre a memória e a história: a problemática dos lugares. Projeto História, 10. São Paulo: PUC.

ORLANDI, E. 1994. Segmentar ou Recortar? Linguística: questões e controvérsias: Série Estudos 10. Uberaba: Fiube. . 2004. A Cidade dos Sentidos. Campinas: Pontes. 2007. As formas de silêncio: no movimento dos sentidos. Campinas: Editora da Unicamp. 2008. Terra à Vista: Discurso do Confronto: Velho e Novo Mundo. Campinas: Unicamp.

PAYER, M. 2005, Março. Linguagem e Sociedade Contemporânea: Sujeito, Mídia e Mercado. Revista Rua, v. 11, Campinas, pp. 9-26.

PÊCHEUX, M. 1998. Semântica e discurso. Uma crítica à afirmação do óbvio. Campinas: Unicamp.

PEIXOTO, N. B. 1999. Intervenções Urbanas. Revista Rua, Número Especial, Campinas: Unicamp, pp. 81-88.

SILVA, H. "Rememoração"/comemoração: as utilizações sociais da memória.2002. Rev. Bras. Hist. vol.22 no.44, São Paulo.

SOUSA, E. L. A. 2000, Abril. Caligrafias de uma subtração. C. da APPOA, v. 78, Porto Alegre, pp. 20-23.

TESSLER, E. 2000, Abril. A instalação enquanto lugar e o lugar do espectador. C. da APPOA, v. 78, Porto Alegre, pp. 33-36.

THIBAUD, J. P. 2008. A ambiência, trilhando caminho - em direção a uma perspectiva internacional. Revista Rua, v.14.1, Campinas. 
VASCONCELOS, D. M. 2008, Dezembro. Violência Política e Direitos Humanos: As Lutas por Verdade, Justiça e Memória na Argentina. Teoria \& Sociedade,16, pp.208243.

2009, Outubro. Memória política, democracia e accountability: algumas reflexões teóricas. Oficina do CES,300. 
Para citar essa obra:

ARAÚJO, Angela de Aguiar; BRASIL, Luciana Leão. Do digital às digitais no Sitio de Memoria (Córdoba, Argentina): (re) interpretações da história política na cidade em movimento. RUA [online]. 2013, no. 19. Volume 1 - ISSN 1413-2109

Consultada no Portal Labeurb - Revista do Laboratório de Estudos Urbanos do Núcleo de Desenvolvimento da Criatividade

http://www.labeurb.unicamp.br/rua/

Capa: FIGUEROA, Pedro Luis. 2011. Museo de lãs memórias - Huellas. Disponível em: http://www.elfoton.es/gallery/v/Ganadores+IX+Concurso+de+Fotografia+Elfoton+2012/Report aje/Reportaje+01+ Copiar.jpg.html

\author{
Laboratório de Estudos Urbanos - LABEURB \\ Núcleo de Desenvolvimento da Criatividade - NUDECRI \\ Universidade Estadual de Campinas - UNICAMP \\ http://www.labeurb.unicamp.br/ \\ Endereço: \\ LABEURB - LABORATÓRIO DE ESTUDOS URBANOS \\ UNICAMP/COCEN / NUDECRI \\ CAIXA POSTAL 6166 \\ Campinas/SP - Brasil \\ CEP 13083-892 \\ Fone/ Fax: (19) 3521-7900 \\ Contato: http://www.labeurb.unicamp.br/contato
}

